\title{
Significance of Expression of Complement C4d in Esophageal Squamous Cell Carcinoma
}

\author{
MAIKO KIKUCHI, MASANOBU NAKAJIMA, HIROTO MUROI, MASAKAZU TAKAHASHI, \\ JUN ITOH, SATORU YAMAGUCHI, KINRO SASAKI and HIROYUKI KATO
}

Department of Surgery I, Dokkyo Medical University, Mibu, Japan

\begin{abstract}
Background/Aim: Esophageal squamous cell carcinoma (ESCC) is one of the most difficult malignancies to cure. C4d is a degradation product of the classical complement pathway and is suggested as an early diagnostic marker for other SCCs. The purpose of this study was to clarify the association of complement C4d with ESCC. Patients and Methods: Immunohistochemical staining for C4d was performed on surgical specimens obtained from 114 patients with ESCC. Results: Positive C4d expression was observed in $70(61.4 \%)$ cases and negative expression in 44 (38.6\%) cases. There was a significant inverse correlation between C4d expression and depth of tumor invasion $(p=0.0001)$, lymph node metastasis $(p=0.011)$, lymphatic invasion $(p=0.033)$, and TNM stage $(p=0.0021)$. KaplanMeier analysis showed that negative $C 4 d$ expression tended to lead to shorter overall survival $(p=0.232)$. Conclusion: C4d expression in ESCC might be useful in developing treatment strategies or suppression of ESCC.
\end{abstract}

Esophageal squamous cell carcinoma (ESCC) is the major histological type of esophageal cancer in East Asian countries (1) and the eighth most common form of cancer worldwide (2). It is one of the most difficult malignancies to cure. It has a poor prognosis compared to other types of digestive cancer because of its high frequency of lymph node metastasis and recurrence (3). The overall 5-year survival rate of patients with ESCC is $<20 \%$ (4), therefore early diagnosis is one of the most important factors for patient survival.

Two hypotheses are proposed for the role of the immune system in cancer initiation and progression. Firstly, the traditional hypothesis is that long-term inflammatory reactions

Correspondence to: Maiko Kikuchi, Department of Surgery I, Dokkyo Medical University, 880 Kitakobayashi Mibu, Shimotsugagun, Tochigi 321-0293, Japan. Tel: +81 282872157, Fax: +81 282866213, e-mail: k-maiko@dokkyomed.ac.jp

Key Words: Esophageal cancer, complement C4d, immune response evasion, immune tolerance. promote cancer progression. Secondly, the cancer immunoediting theory postulates that the immune system protects the host against cancer development (5-11). Complement is a central component of innate immunity and plays an essential role in immune surveillance and homeostasis (12). The complement system is an essential part of the inflammatory response and innate immunity to infection (13).

In various tumor types, complement activation, particularly of the classical pathway, is reported to be related to carcinogenesis (14-16). C4d is a degradation (activation) product of the classical complement pathway. It is suggested that $\mathrm{C} 4 \mathrm{~d}$ is a useful early diagnostic marker in lung cancer or oropharyngeal SCC and related to their prognosis $(17,18)$.

The purposes of the present study were to analyze the clinical significance of C4d in ESCC by immunohistochemistry, and to examine the relationship between $\mathrm{C} 4 \mathrm{~d}$ expression and clinicopathological parameters and patient survival.

\section{Patients and Methods}

Patient characteristics. Between May 2009 and March 2015, 199 patients with ESCC underwent transthoracic esophagectomy by the McKeown technique at the Dokkyo Medical University Hospital, Japan. Surgical tissue samples were obtained from 114 patients, which excluded 69 patients who had received neoadjuvant therapy and 16 who underwent salvage surgery. There were 97 male $(85.1 \%)$ and 17 female $(14.9 \%)$ patients, with a mean age of 69 years (range $=40-86$ years). Tumor stage and disease grade were classified according to the seventh edition of the TNM classification of the International Union Against Cancer (UICC) (19). All patients signed informed consent forms according to our institutional guidelines.

Immunohistochemistry. Resected specimens were fixed with $10 \%$ neutral-buffered formalin and embedded in paraffin blocks. Fourmicrometer-thick sections were deparaffinized with xylene, hydrated through a series of graded alcohol solutions, and immersed in $3 \%$ hydrogen peroxide in absolute methanol for $30 \mathrm{~min}$. The sections were washed with distilled water and phosphate-buffered saline (PBS; pH 6.0). Antigens were retrieved by immersion in preheated $0.01 \mathrm{M}$ citrate buffer ( $\mathrm{pH} 6.0$ ) and heating in an autoclave at $120^{\circ} \mathrm{C}$ for $20 \mathrm{~min}$. The sections were incubated with rabbit anti-C4d polyclonal antibody (1: 50 dilution; Biomedica, Vienna, Austria) at 
room temperature for $1 \mathrm{~h}$ in a high-humidity chamber. After washing in PBS, the sections were incubated with biotinylated antirabbit IgG for $30 \mathrm{~min}$ at room temperature, followed by incubation with an avidin-biotin-peroxidase complex solution (VECTASTAIN ${ }^{\circledR}$ ABC Kit; Vector Laboratories, Burlingame, CA, USA). Peroxidase activity was visualized by incubation in $0.02 \%$ 3,3'-diaminobenzidine tetrahydrochloride with hematoxylin, dehydrated, and mounted in aqueous medium. C4d staining was evaluated by two pathologists blinded to the clinicopathological background of the patients. Normal epithelial tissue, present on each slide, was used as internal control. Negative C4d expression was defined as identical or weaker staining than in the internal control, and positive $\mathrm{C} 4 \mathrm{~d}$ expression was defined as stronger staining than in the internal control.

Statistical analysis. Statistical analysis was performed by $\chi^{2}$ and $t$ tests. Survival parameters were determined using the Kaplan-Meier method and compared using the log-rank test. Univariate and multivariate survival analyses were performed using the Cox proportional hazards regression model. A value of $p<0.05$ was considered statistically significant in all analyses.

\section{Results}

Immunohistochemistry for $C 4 d$. Representative results of immunohistochemistry for $\mathrm{C} 4 \mathrm{~d}$ are shown in Figure 1. In normal squamous epithelium of the esophagus, C4d staining was positive in the cytoplasm of the basal layer (Figure 1a). In ESCC, C4d staining in the cytoplasm varied among tumor tissues. Several staining patterns were observed for $\mathrm{C} 4 \mathrm{~d}$ expression in the same tumor tissues. We evaluated $\mathrm{C} 4 \mathrm{~d}$ staining at the invasive front of the tumor tissue. We defined identical or weaker staining in ESCC than in normal squamous epithelium as negative $\mathrm{C} 4 \mathrm{~d}$ expression, and stronger staining in ESCC than in normal squamous epithelium as positive $\mathrm{C} 4 \mathrm{~d}$ expression.

Relationship between C4d expression and clinicopathological findings. The relationship between $\mathrm{C} 4 \mathrm{~d}$ expression and clinicopathological characteristics is shown in Table I. Positive C4d expression was observed in 70 (61.4\%) cases and negative expression in $44(38.6 \%)$. There was a significant inverse correlation between $\mathrm{C} 4 \mathrm{~d}$ expression and depth of tumor invasion ( $p=0.0001)$, lymph node metastasis $(p=0.011)$, lymphatic invasion $(p=0.033)$, and TNM stage $(p=0.0021)$. There was a significant correlation between $\mathrm{C} 4 \mathrm{~d}$ expression and tumor location $(p=0.001)$. However, there was no significant association with patient age, gender, or blood vessel invasion.

Relationship between C4d and survival. Kaplan-Meier analysis showed that negative $\mathrm{C} 4 \mathrm{~d}$ expression tended to lead to shorter overall survival $(p=0.232)$ (Figure 2a). No association was found between $\mathrm{C} 4 \mathrm{~d}$ staining and disease-free survival (Figure 2b). Multivariate analysis also showed no significant association.
Table I. Relationship between C4d expression and clinicopathological characteristics in patients with esophageal squamous cell carcinoma.

\begin{tabular}{|c|c|c|c|}
\hline \multirow[b]{2}{*}{ Factor } & \multicolumn{2}{|c|}{ C4d expression, $\mathrm{n}$} & \multirow[b]{2}{*}{$p$-Value } \\
\hline & $\begin{array}{c}\text { Negative } \\
n=44\end{array}$ & $\begin{array}{c}\text { Positive } \\
n=70\end{array}$ & \\
\hline Age (years) & $67.6 \pm 7.75$ & $68.3 \pm 9.03$ & 0.688 \\
\hline \multicolumn{4}{|l|}{ Gender } \\
\hline Male & 37 & 60 & \multirow[t]{2}{*}{0.795} \\
\hline Female & 7 & 10 & \\
\hline \multicolumn{4}{|l|}{ Location } \\
\hline Upper & 0 & 11 & \multirow[t]{3}{*}{0.001} \\
\hline Middle & 19 & 38 & \\
\hline Lower & 25 & 21 & \\
\hline \multicolumn{4}{|l|}{ Depth } \\
\hline $\mathrm{T} 1$ & 9 & 43 & \multirow[t]{4}{*}{0.0001} \\
\hline $\mathrm{T} 2$ & 7 & 4 & \\
\hline $\mathrm{T} 3$ & 24 & 21 & \\
\hline $\mathrm{T} 4$ & 4 & 2 & \\
\hline \multicolumn{4}{|c|}{ Lymph node metastasis } \\
\hline Absent & 20 & 49 & \multirow[t]{2}{*}{0.011} \\
\hline Present & 24 & 21 & \\
\hline \multicolumn{4}{|c|}{ Lymphatic invasion } \\
\hline Absent & 18 & 44 & \multirow[t]{2}{*}{0.033} \\
\hline Present & 26 & 26 & \\
\hline \multicolumn{4}{|c|}{ Venous invasion } \\
\hline Absent & 12 & 31 & \multirow[t]{2}{*}{0.077} \\
\hline Present & 32 & 39 & \\
\hline \multicolumn{4}{|l|}{ Stage } \\
\hline 0 & 0 & 4 & \multirow[t]{4}{*}{0.0021} \\
\hline $\mathrm{I}$ & 11 & 38 & \\
\hline II & 12 & 10 & \\
\hline III & 21 & 18 & \\
\hline
\end{tabular}

\section{Discussion}

There are three complement activation pathways: classical, mannose-binding lectin, and alternative. The three complement pathways converge in the activation of $\mathrm{C} 3$, finally forming the membrane attack complex (MAC), which causes cell death (20). C4d is produced by the classical pathway, which is activated by $\mathrm{C} 1$ qrs complex and derives from $\mathrm{C} 4 \mathrm{~b}$, which has an internal thioester in the molecule. When $\mathrm{C} 4 \mathrm{~d}$ is cleaved from $\mathrm{C} 4 \mathrm{~b}$, the covalent bond between $\mathrm{C} 4 \mathrm{~d}$ and the tissue membrane remains intact. Covalentbound $\mathrm{C} 4 \mathrm{~d}$ has a longer half-life, and therefore remains at the site (21). According to this theory, the tissue membrane should be stained for C4d. However, in our study, C4d staining was mainly in the cytoplasm and membrane.

Covalent-bound $\mathrm{C} 4 \mathrm{~d}$ is used for immunological evaluation. For example, $\mathrm{C} 4 \mathrm{~d}$ is used as a marker for antibody-mediated rejection (AMR) of renal allografts. Diagnostic criteria for AMR of renal allografts have been established, and quantitative cut-off values for $\mathrm{C} 4 \mathrm{~d}$ added to 

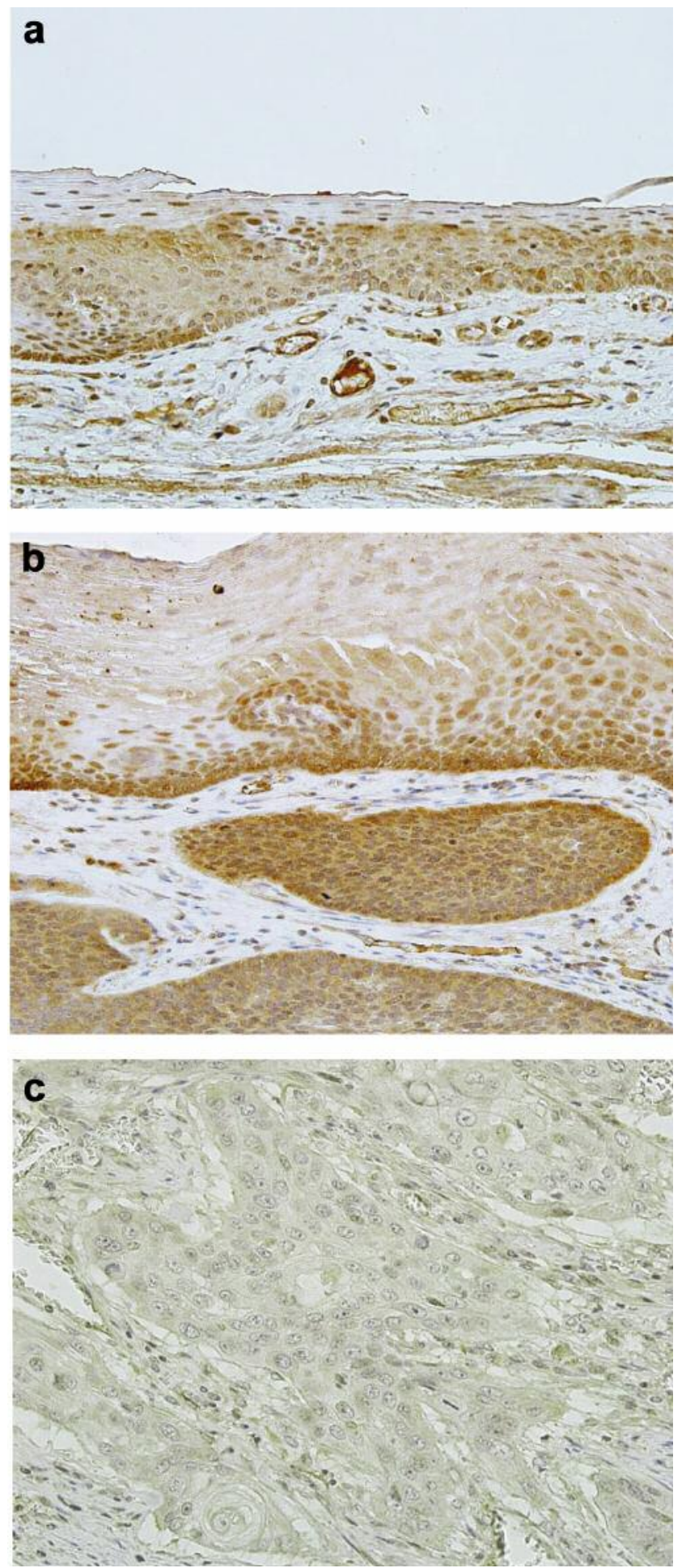

Figure 1. Representative results of immunohistochemistry for C4d. a: C4d expression in normal squamous epithelium of the esophagus. $C 4 d$ staining was positive in the cytoplasm of the basal layer. $b$ : Positive $C 4 d$ expression was stronger in esophageal squamous cell carcinoma (ESCC) than normal squamous epithelium. $c$ : Negative C4d expression was defined as identical or weaker staining in ESCC than in normal squamous epithelium.
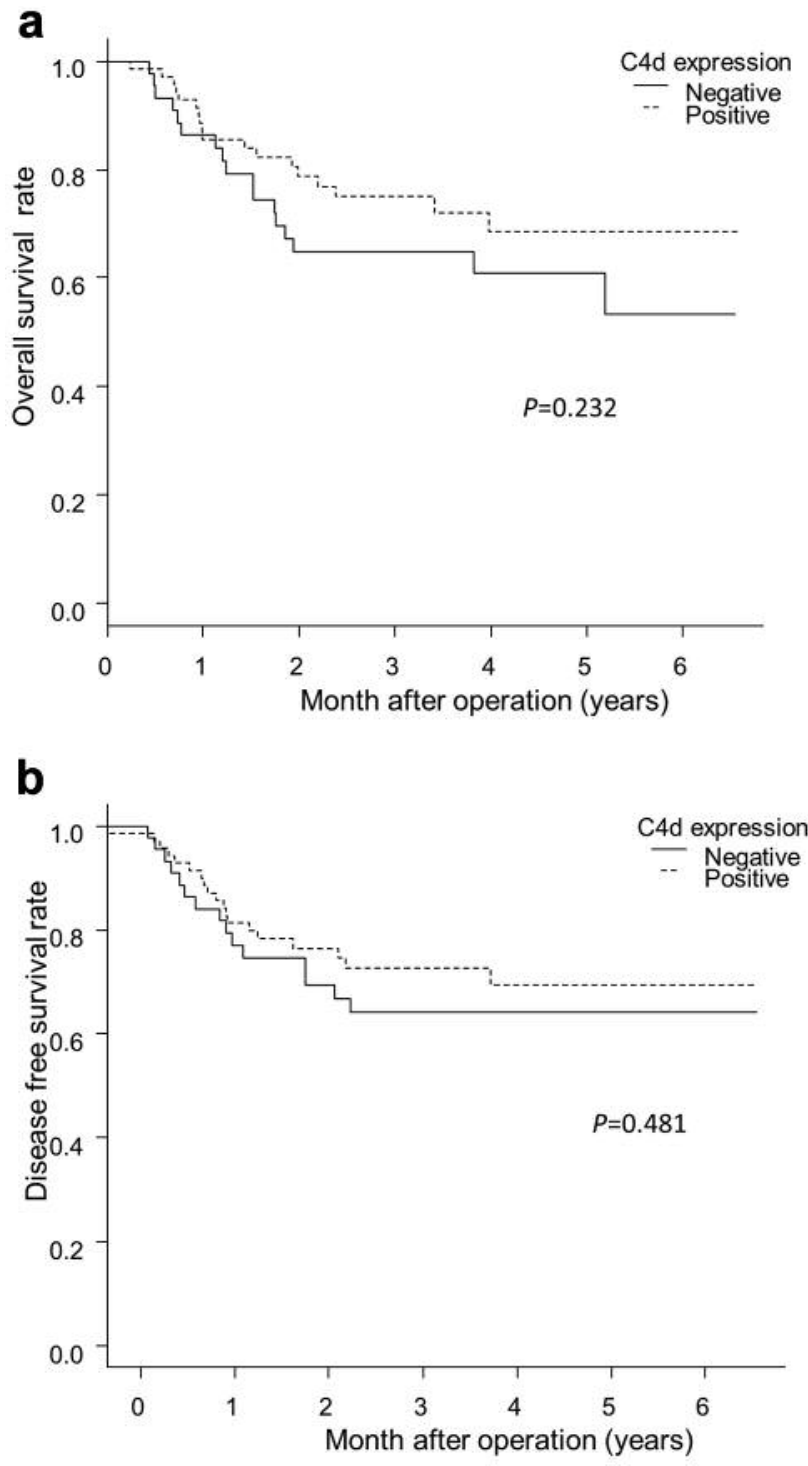

Figure 2. Relationship between C4d expression and postoperative overall (a) and disease-free (b) survival. The 5-year overall survival rate in patients with negative C4d expression was $61.0 \%$ and $68.6 \%$ in those with positive $C 4 d$ expression. Negative $C 4 d$ expression tended to lead to shorter overall survival than positive C4d expression did. The 5 -year disease-free survival rate in patients with negative $C 4 d$ expression was $64.3 \%$ and $69.4 \%$ in those with positive C4d expression. No association was found between C4d staining intensity and diseasefree survival.

the Banff criteria (22). C4d expression in peritubular capillaries is one of the diagnostic criteria of AMR. C4d expression reflects the function of the immune system that removes non-self tissue. Therefore, it is possible that the negative $\mathrm{C} 4 \mathrm{~d}$ expression in the current study reflected an aberrant immune response as a result of immune evasion. 
Our study showed that negative $\mathrm{C} 4 \mathrm{~d}$ expression was associated with progression of ESCC, advanced depth of tumor invasion, lymph node metastasis, lymphatic invasion, and TNM stage. C4d expression and tumor location were significantly correlated. We hypothesize that advanced cancer may inactivate the immune system and suppress expression of $\mathrm{C} 4 \mathrm{~d}$.

Corrales et al. have suggested that complement-deficient mice have decreased tumor growth compared with wild-type mice $(5,23,24)$. Ajona et al. reported positive $\mathrm{C} 4 \mathrm{~d}$ expression to be associated with progression of cancer, such as depth of tumor invasion, lymph node metastasis, and TNM stage, or prognosis of the disease in oropharyngeal or lung cancer (17, 18). From these reports, we suggest that complement activation promotes carcinogenesis. Hence, we believe complement activation is related to the traditional hypothesis.

In contrast, our study showed the relationship between negative $\mathrm{C} 4 \mathrm{~d}$ expression and advanced cancer. This suggests that negative $\mathrm{C} 4 \mathrm{~d}$ expression induces immune response evasion, that is, immune tolerance. Immune tolerance might inhibit cell death induced by MAC. If cancer cell death is not induced, cancer cells continue to grow and carcinogenesis is promoted. MAC might contribute to the increase in cancer cells in advanced ESCC, while MAC removes cancer cell in other tumor types. This might apply to the immunoediting theory in ESCC.

Ajona et al. showed by computed tomography that plasma C4d levels in asymptomatic patients with lung cancer (histologically, $53.6 \%$ of patients had adenocarcinoma and $46.4 \%$ had SCC) were higher than in controls (18). The plasma C4d level may be a sensitive screening marker. Patients diagnosed with stage I lung cancer had lower plasma C4d levels than those diagnosed with stage II disease. Higher C4d expression evaluated by immunohistochemistry and a higher plasma $\mathrm{C} 4 \mathrm{~d}$ level resulted in significantly worse overall survival. These results suggest that plasma $\mathrm{C} 4 \mathrm{~d}$ levels may predict the risk of lung cancer in asymptomatic individuals and be of value in early diagnosis. In our study, patients with early-stage ESCC had higher levels of C4d expression than those with advanced-stage disease. Consequently, evaluation of $\mathrm{C} 4 \mathrm{~d}$ expression may be useful as a screening tool in ESCC. However, in advanced ESCC, the evaluation of $\mathrm{C} 4 \mathrm{~d}$ expression would not be useful for screening because of decreased $\mathrm{C} 4 \mathrm{~d}$ expression. Ajona et al. examined immunohistochemistry as well as plasma $\mathrm{C} 4 \mathrm{~d}$ levels in patients with lung cancer (18). Therefore, the role of C4d in ESCC should be examined by other procedures. The expression of complement protein and induction of cancer initiation and progression by complement may differ in each type of tumor.

Patients with upper thoracic ESCC have more superficial tumor invasion than patients with middle or lower thoracic ESCC. This suggests that there might be a significant relationship between $\mathrm{C} 4 \mathrm{~d}$ expression and tumor location. However, we considered that there is no relationship between C4d expression and tumor location. Our statistical analysis showed that there was no significant relationship between C4d expression and patient prognosis. Most of our patients had early-stage ESCC, which might have been a factor in this result.

Finally, we indicated that C4d might be useful for early diagnosis in ESCC. If complement activation can be stopped at the stage where $\mathrm{C} 4 \mathrm{~d}$ is cleaved from $\mathrm{C} 4 \mathrm{~b}$, such as C1qrs complex, it might be possible to suppress the development of ESCC. A study on the relation between immune response and carcinogenesis of $\mathrm{C} 4 \mathrm{~d}$ may be useful in the early diagnosis, treatment planning, and suppression of ESCC.

In conclusion, the expression of $\mathrm{C} 4 \mathrm{~d}$ was lower in advanced than in early ESCC and normal squamous epithelium of the esophagus. Moreover, a lower expression of $\mathrm{C} 4 \mathrm{~d}$ tended to lead to shorter overall survival. Further research is needed to establish the role of C4d in ESCC, and for its use in early diagnosis and treatment of ESCC.

\section{Acknowledgements}

This study was supported by the Uehara Memorial Foundation. The authors would like to thank H. Ozeki, Y. Ohashi and N. Yuzawa for their secretarial assistance and N. Suzuki, a member of the Research Support Center Division of Clinical Science, for her technical assistance.

\section{References}

1 Nakajima $\mathrm{M}$ and Kato $\mathrm{H}$ : Treatment options for esophageal squamous cell carcinoma. Expert Opin Pharmacother 14: 13451354, 2013.

2 Kato $\mathrm{H}$ and Nakajima M: Treatments for esophageal cancer: a review. Gen Thorac Cardiovasc Surg 61: 330-335, 2013.

3 Kato H, Fukuchi M, Miyazaki T, Nakajima M, Tanaka N, Inose T, Kimura H, Faried A, Saito K, Sohda M, Fukai Y, Masuda N, Manda R, Ojima H, Tsukada K and Kuwano H: Surgical treatment for esophageal cancer: current issues. Dig Surg 24: 8895, 2007.

4 Muroi H, Nakajima M, Satomura H, Takahashi M, Yamaguchi S, Sasaki K, Yokobori T, Miyazaki T, Kuwano H and Kato H: Low PHLDA3 expression in oesophageal squamous cell carcinomas is associated with poor prognosis. Anticancer Res 35: 949-954, 2015.

5 Markiewski MM, DeAngelis RA, Benencia F, RicklinLichtsteiner SK, Koutoulaki A, Gerard C, Coukos G and Lambris JD: Modulation of the antitumor immune response by complement. Nat Immunol 9: 1225-1235, 2008.

6 Dunn GP, Bruce AT, Ikeda H, Old LJ and Schreiber RD: Cancer immunoediting: from immunosurveillance to tumor escape. Nat Immunol 3: 991-998, 2002.

7 Swann JB and Smyth MJ: Immune surveillance of tumors. J Clin Invest 117: 1137-1146, 2007.

8 Coussens LM and Werb Z: Inflammation and cancer. Nature 420: 860-867, 2002. 
9 Balkwill $\mathrm{F}$ and Mantovani A: Inflammation and cancer: back to Virchow? Lancet 357: 539-545, 2001.

10 Bhardwaj N: Harnessing the immune system to treat cancer. J Clin Invest 117: 1130-1136, 2007.

11 Lin WW and Karin M: A cytokine-mediated link between innate immunity, inflammation, and cancer. J Clin Invest 117: 1175$1183,2007$.

12 Ricklin D, Hajishengallis $\mathrm{G}$, Yang $\mathrm{K}$ and Lambris JD: Complement: a key system for immune surveillance and homeostasis. Nat Immunol 11: 185-797, 2010.

13 Markiewski MM and Lambris JD: The role of complement in inflammatory diseases from behind the scenes into the spotlight. Am J Pathol 171: 715-727, 2007.

14 Ytting H, Jensenius JC, Christensen IJ, Thiel S and Nielsen HJ: Increased activity of the mannan-binding lection complement activation pathway in patients with colorectal cancer. Scand J Gastroenterol 39: 674-679, 2004.

15 Bjørge L, Hakulinen J, Vintermyr OK, Jarva H, Jensen TS, Iversen $\mathrm{OE}$ and Meri S: Ascitic complement system in ovarian cancer. Br J Cancer 92: 895-905, 2005

16 Corrales L, Ajona D, Rafail S, Lasarte JJ, Riezu-Boj JI, Lambris JD, Rouzaut A, Pajares MJ, Montuenga LM and Pio R: Anaphylatoxin C5a creates a favorable microenvironment for lung cancer progression. J Immunol 189: 4674-4683, 2012.

17 Ajona D, Pajares MJ, Chiara MD, Rodrigo JP, Jantus-Lewintre E, Camps C, Suarez C, Bagán JV, Montuenga LM and Pio R: Complement activation product $\mathrm{C} 4 \mathrm{~d}$ in oral and oropharyngeal squamous cell carcinoma. Oral Dis 21: 899-904, 2015.

18 Ajona D, Pajares MJ, Corrales L, Perez-Gracia JL, Agorreta J, Lozano MD, Torre W, Massion PP, de-Torres JP, Jantus-Lewintre E, Camps C, Zulueta JJ, Montuenga LM and Pio R: Investigation of complement activation product $\mathrm{C} 4 \mathrm{~d}$ as a diagnostic and prognostic biomarker for lung cancer. J Natl Cancer Inst 105: 1385-1393, 2013.
19 International Union Against Cancer: TNM Classification of Malignant Tumors. Seventh Edition. Sobin LH, Wittekind C and Gospodarowicz M (eds.). Willey-Blackwell. Oxford, 2009.

20 Murata K and William MB III: Mechanisms of complement activation, C4d deposition, and their contribution to the pathogenesis of antibody mediated rejection. Transplant Rev 23: 139-150, 2009.

21 Cohen D, Colvin RB, Daha MR, Drachenberg CB, Haas M, Nickeleit V, Salmon JE, Sis B, Zhao MH, Bruijn JA and Bajema IM: Pros and cons for $\mathrm{C} 4 \mathrm{~d}$ as a biomarker. Kidney Int 81: 628639, 2012.

22 Kohei N, Tanabe T, Horita S, Omoto K, Ishida H, Yamaguchi Y and Tanabe K: Sequential analysis of donor-specific antibodies and pathological findings in acute antibody-mediated rejection in a rat renal transplantation model. Kidney Int 84: 722-732, 2013.

23 Nunez-Cruz S, Gimotty PA, Guerra MW, Connolly DC, Wu YQ, DeAngelis RA, Lambris JD, Coukos G and Scholler N: Genetic and pharmacologic inhibition of complement impairs endothelial cell function and ablates ovarian cancer neovascularization. Neoplasia 14: 994-1004, 2012.

24 Pio R, Corrales L and Lambris JD: The role of complement in tumor growth. Adv Exp Med Biol 772: 229-262, 2014.
Received July 23, 2016

Revised August 6, 2016

Accepted August 18, 2016 